\title{
MİKROORGANİZMALARDA ÇOĞUNLUĞU ALGILAMA VE ÇOĞUNLUĞU ALGILAMA MEKANIZZMASININ ENGELLENMESİ
}

\author{
Işı1 Var*, Çağrı Çelik \\ Çukurova Üniversitesi, Ziraat Fakültesi, Gıda Mühendisliği, Adana, Türkiye
}

Geliş / Received: 19.05.2019; Kabul / Accepted: 16.09.2019; Online bask1 / Published online: 07.10.2019

Var, I., Çelik, Ç. (2019). Mikroorganizmalarda çoğunluğu alg1lama ve çoğunluğu alg1lama mekanizmasinın engellenmesi. GIDA (2019) 44 (6): 943-953 doi: 10.15237/gida.GD19016

Var, I., Celik, C. (2019). Quorum sensing and quorum quenching mechanism in microorganisms. GIDA (2019) 44 (6): $943-953$ doi: $10.15237 /$ gida.GD19016

\section{öz}

Hücreler arası iletişim ya da çoğunluğu algılama olarak bilinen Quorum Sensing (QS) mekanizması ile gida kaynaklı patojenler biyofilm, antibiyotik direnci ve virülans gibi etkileri oluşturarak halk sağlığını tehdit etmektedir. QS bakteriler, küfler ve mayalar gibi çeşitli mikroorganizmalarda görülmektedir. QS mekanizmasında hücreler arası iletişimde kullanılan iletișim molekülü olarak otoindükleyiciler görev almaktadır ve bu moleküllerin mikroorganizmalara göre çeşitlilik göstermesi QS mekanizmasının kontrolünü güçleştirmektedir. QS engelleme mekanizması olarak bilinen Quorum Quenching (QQ) konusunda ise son yıllarda birçok çalışma yapılmaktadır. QQ mekanizması enzimatik ve kimayasal olarak doğada bulunabilmekte ve bunun yanı sıra bitkisel gidaların ekstraktları da QS mekanizması sinyallerine kimyasal olarak benzediğinden bu amaçla kullanılmakta ve onları inhibe etmektedir. Bu derlemede halk sağlığı için birçok disiplinde olduğu gibi gıda sektöründe de çok ciddi tehlikelere sebep olan mikroorganizmalardaki QS mekanizması ve bu mekanizmanın zararlı etkilerinin önlenmesini konu alan QQ mekanizması ele alınmışır. Anahtar kelimeler: Mikroorganizmalarda çoğunluğu algılama, hücreler arası iletişim, küfler, mayalar, antibiyotik direnci

\section{QUORUM SENSING AND QUORUM QUENCHING MECHANISM IN MICROORGANISMS}

\begin{abstract}
Quorum sensing (QS), is cell to cell comunication, threatens on public health to make effects by means of biofilm, antibiotic resistance and virulence. QS observed in bacteria, molds and yeasts. Autoinducers are most important communication molecules in QS. And the diversity of these molecules according to microorganisms makes the control of the QS mechanism difficult. In recent years, there is a lot of work about Quorum Quenching (QQ) which is known as blocking mechanism of the QS. The QQ mechanism exists both enzymatically and chemically in nature and the extracts of plant-origin food has ability inhibited autoinducers owing to the fact that they are chemically similar to autoinducers. In this review, the QS mechanism in microorganisms that cause serious hazards in the food sector as well as in many disciplines for public health and the QQ mechanism intended to prevent the harmful effects of QS are discussed.
\end{abstract}

Keywords: Quorum sensing, quorum quenching, molds, yeasts, antibiotic resistance

\footnotetext{
${ }^{*}$ Yazışmadan sorumlu yazar/Corresponding author

$\triangle$ ivar@cu.edu.tr (6) (+90) 5448274245 


\section{GİRİ̧̧}

Mikroorganizmalar çevrelerinden izole olarak yaşamayıp diğer mikroorganizmalar ile sürekli iletişim halindedir, sinyal molekülleri ile meydana gelen bu hücre-hücre iletişim mekanizmasina Quorum Sensing (QS) denilmektedir (Barriuso vd., 2018). Bu mekanizma hücre popülasyon dengesine bağlı olan hücre-hücre iletişim sistemlerinden biridir (Okutsu vd., 2016). Quorum Sensing virülans faktör, sporilizasyon, mortalite, toksin üretimi ve biyofilm oluşturma gibi önemli mikrobiyal süreçleri düzenler (DuanisAssaf vd., 2016). Kısaca hücreler arası iletişim için kullanılan dil denilebilmektedir (Deep vd., 2011). Bu hücreler arasındaki iletişim patojen bakterilerin gidalarda olumsuz etkilerini de arttırmaktadır. $\mathrm{Bu}$ bağlantının inhibe edilmesi gıda güvenliği için önemli bir yöntem olabilmektedir (Duarter vd., 2016). QS'in önemi sadece gida güvenliği için değil tıp, çevre ve tarım ile ilgili disiplinlerde de söz konusudur (Karaboz ve Sukatar, 2004).

QS mekanizması biyofilm, virülans etkinin yanı sıra antibiyotik direnci gibi etkileri oluşturması ile halk sağlı̆̆ını da tehdit etmektedir (Dong vd., 2007). Özellikle patojenlerin antibiyotik direnci son yıllarda dikkate değer bir şekilde artmıştır (Bhardwaj vd., 2013). Mikroorganizmalardaki bu antibiyotik direnci tedavide çeşitli komplikasyonların, hataların ve ölümlerin oluşmasına neden olmaktadır (Wang vd., 2013).

QS mekanizmasını önlemek için kullanılan tüm sistemler Quorum Quenching (QQ) olarak isimlendirilmektedir. Bu sistem patojenlerin QS mekanizmasında ürettikleri otoindükleyicileri bloke ederek hücreler arası iletişimi engellemek temellidir (Chen vd., 2013).

$\mathrm{Bu}$ derlemede halk sağlığ1 ve özellikle gıda sektöründe çok ciddi tehlikelere sebep olan mikroorganizmalarda tanımlanan Quorum Sensing ve bu mekanizmanın zararlı etkilerini durdurabilmek için kullanılan Quorum Quenching mekanizmaları ele alınmıştır.

\section{QUORUM SENSING MEKANIZZMASI} Bakterilerde Quorum Sensing Mekanizmas1 Quorum Sensing ilk olarak akuatik ortamlarda ve su altında yaşayan canlılarla patojenik veya mutualistik yaşayan bir tür olan ve 1ş1k yayan Photobacterium fischeri (Vibrio fischeri) bakterilerinde tanımlanmıştır (Barrios vd., 2006; Amaral vd., 2015). Ken Nealson, Terry Platt ve Woody Hastings 1970 yllında yayınlanan makaleleri ile bu tanımlamay ilk defa yaparak mikroorganizmalar hakkında devrim niteliğinde bir öngörüyü oluşturmuşlardır (O’Toole, 2016). İsim olarak Quorum Sensing ifadesi ise Fuqua ve ark., tarafindan 1994 yilında yapılan çalışmada geçmektedir. Hatta bu mekanizmanın neoDarwinizmin evrim teorisinde açıklanan ilk çok hücreli organizmanın ortaya çıkmasında önemli unsurlarından biri olduğu ve bu aşamada rol oynamış olabileceği yönünde görüşler ileri sürülmektedir (Barriuso vd., 2018).

Yapılan çalşmalarda Quorum Sensing üç temel kısma ayrilarak incelenmektedir. İlk kısım hücre topluluğunun salg1ladığ1 sinyal moleküllerinin oluşumudur (Hawver vd., 2016). Bu sinyal molekülleri kisaca hücre-hücre sinyal mekanizmas1 olan Quorum Sensing sirasinda otoindükleyici olarak bilinen belirli bakterilere özgü hücresel fonksiyonları harekete geçiren moleküllerdir (Almasoud vd., 2015). Genel olarak bu sinyaller hem hücre yoğunluğuna hem de biyofilm oluşumuna yardımcı olmak için çeşitli fizyolojik aktiviteleri düzenlerler (Blana vd., 2017). Örneğin QS yapan bakterilerin düşük hücre yoğunluğunda (low cell density) olduğu ortamlarda otoindükleyiciler de az miktarda bulunmakta olup hücre yoğunluğunu arttırmaya yardımcı olmak için hücre dışına salgilandıkları görülmüştür. (Rutherfor ve Bassler, 2012).

$\mathrm{Bu}$ sinyaller temel olarak ikiye ayrilmaktadır. Birincisi aminoasitler ve kisa peptitler, yaygin olarak Gram pozitif bakteriler tarafindan kullanılır ve ikincisi yağ asidi türevleri, sıklıkla Gram negatif bakteriler tarafindan kullanılır (Whitehead vd., 2001). Son yirmi yılda yapılan çalışmalarda bu sinyal moleküllerinin birçoğu tanımlanmıştır. Genel olarak sinyal moleküllerine N-acylated-Lhomoserine lactones (AHL) Gram negatif bakteriler için, otoindükleyici peptitler (Autoinducing peptides;AIP) ise Gram pozitif bakterilerde örnek olarak verilmektedir. Bu iki temel gruba ek olarak hem Gram pozitif hem de 
Gram negatif bakterilerde görülen Autoinducer-2 (AI-2) molekülleri de bulunmaktadır (BosgelmezTinaz, 2013).

$\mathrm{Bu}$ sinyallerden AHLs homolog proteinler tarafindan sentezlenmektedir (Anbazhagan, 2012). AHLs yapisinda 4-18 karbonlu ve acly zincirleri taşıyan bir homoserin lakton halkası içerir. Kısa zincirli olanları bakteri hücre membranı boyunca dağılırken, uzun zincirli olanları yüksek konsantrasyonlu bölgelere moleküllerin aktif taşınmasında kullanılır (Johensen ve Jespersen, 2017). Bunun yaninda AHL'ler, S-adenosilmetionin (SAM) ile bir aclyacly taşıyıcı protein reaksiyonuyla sentezlenir. $\mathrm{Bu}$ protein genellikle AHL sintazlarının LuxI ailesinin bir enzimi tarafindan gerçekleştirilir ve LuxR ailesinin transkripsiyon düzenleyicileri tarafindan algilanır (Skandamis ve Nychas, 2012). Hücre popülasyonuna bağlı olarak AHL konsantrasyonu hücre içinde eşik değeri konsantrasyonuna ulaşır ve genellikle LuxR reseptörlerine bağlanırlar (Zan vd., 2012). V. fischeri için biyolüminesans ifadesini düzenleyen temel işlem olan bu sistem ilk olarak Eberhard ve ark. (1981) tarafindan tanımlanmıştır (Erzinger vd., 2018). Eberhard ve ark. (1981) HPLC ile $V$. fischerinin 1 ş1k yayma mekanizmasında bulunan otoindükleyicileri tespit ve sentezi için yaptıkları çalışma sonucu bu otoindükleyicilerin spesifik genetik bir regülatör olduğu ve ayrı bir enzim sistemi ile bağlantilı olduğunu gözlemlemişlerdir (Eberhard vd., 1981). $\mathrm{Bu}$ enzim sisteminde Lux geninin LuxP, LuxQ, LuxU ve LuxO homologlarının görev aldıkları görülmektedir. Farklı bakterilerde aynı görevi yapmalarına rağmen Lux döngülerinde fakllikklar gözlenmektedir. Örneğin Lux homologları $V$. harveyi ve $V$. fisheri bakterilerinin ikisinde de biyolüminesans özellikteyken $V$. fisheri bakterisinde biyofilm oluşumunda da görev almaktadır (Ray ve Visick, 2012). Bu gibi genetik faktörler dişında sıcaklık, $\mathrm{pH}, \mathrm{NaCl}$, gelişme ortamı, inokulum miktarıve bakteri gelişme fazı dâhil olmak üzere AHL'lerin konsantrasyonunu ve türünü etkileyen çeşitli faktörler olabilmektedir (Skandamis ve Nychas, 2012).

Diğer bir sinyal AIPs ise 7-9 aminoasit olarak değişen uzunlukta olup 2-4 aminoasit içeren kuyruk yapısını da bulundurmaktadır (Johnson vd., 2015). Genel olarak AIP’ler doğal ribozom sentezi yoluyla aktif olmayan pro-peptidler olarak ifade edilir ve daha sonra aktif QS sinyali üretmek üzere işlenir ve modifiye edilirler (Rampioni vd., 2014).

QS sinyali olarak AIP'leri kullanan en yaygin patojen Staphylococcus aureus olarak bilinmektedir (Vasquez vd., 2017). Bu patojende virülans proteinlerini kontrol eden merkez transkripsiyon gen olarak agr geni görev almaktadır (Traber vd., 2008). Staphylococcus aureus agr geni A'dan D'ye kadar isimlendirilerek 4 protein grubundan meydana gelmiştir (Vasquez vd., 2017). Bu gruplardan $a g r \mathrm{~B}$ ve $a g r \mathrm{D}$ AIP'lerin sentezi, taşınması ve olgunlaşmasında rol oynarken, $a g r \mathrm{C}$ geni ise bu sinyal molekülünün hücre zar1 tarafindan algilanmasını sağlayan AgrC proteinini kodlar (Roux vd., 2014). Meydana gelen AgrC proteini membrana bağlı olan reseptör-histidin kinaz yapıdadır (Wang vd., 2014). AgrC proteini AIP'leri alg1lar ve bakteri eşik yoğunluğuna ulaştı̆̆nnda aktifleşir (Wang vd., 2017). AgrC AIP'ler ile bağlanma işleminden sonra fosforil grubunu hücre içine aktarır (Wang vd., 2014). Bu aktarılan fosforil grubu QS mekanizmasinın bir sonraki aşamasında kullanılmaktadır (Wang vd., 2017). Son grup olan agrA geni ise Staphylococcus aureus'un virülans etki yaratmasını ya da QS mekanizmasını oluşturmasını sağlar (Vasquez vd., 2017). QS mekanizmasını oluşturan agrA geninin kodladığ1 RNAII mRNA's1 ile P2 destekleyicisi AgrD proteinini sentezleyerek AIP sinyal molekülünü meydana getirir (Roux vd., 2014).

Otoindükleyici (Autoinducer-2;AI-2) ise spesifik olmayan bir molekül olup birçok farklı bakteri türünün AI-2'nin metabolik öncülü olan 4,5dihidroksi-2,3-pentandion'nu (DPD) salg1ladığ1 bildirilmiştir. Bu molekülden türeyen AI-2 sinyal molekülü ya bakterilerin kendileri tarafindan salg1lanmakta ya da bir başka bakteri tarafindan salgılanarak diğer bakterilerin kullanımına sunulmaktadır. Bakterilerdeki bu mekanizma spontane olarak gerçekleştiği gibi ortamda karışık yapıda bulunan bileşiklerin bir başka bakteri tarafindan algilanması ile de gerçekleşebilmektedir (Song vd., 2014). Genel olarak E. coli ve Salmonella 
türleri hücre dışı olarak hem kendi türleri arasında hem de başka türler arasında QS mekanizması için AI-2 sinyal moleküllerini salgilamaktadır (Kendal ve Sperandio, 2014). Yapilan çalışmalarda AI-2 otoindükleyicinin üretiminde bir genin görev aldığı görülmekte ve bu görev alan genin luxS geni olduğu bildirilmektedir (Wang vd., 2005).

QS mekanizmasının ikincisi kısmı ise otoindükleyicilerin sitoplazmada veya zar içerisinde bulunan reseptörler tarafindan tespit edilmesidir (Hawver vd., 2016). Reseptör ve otoindükleyiciler arasındaki ilişkiye bakıldığında Hafnia alvei gibi bakteriler tarafindan salgilanan AHLs molekülleri hem hücre içinde hem de hücre dışında diğer bakterilerin reseptörleri ile algılanır (Blana vd., 2017). H. alvei, bitkiler ve sebzelere ek olarak memelilerin gastrointestinal sistemlerinde de bulunan bir gram-negatif bakteridir (Litrenta ve Oetgen, 2017). Bu bakterinin ürettiği AHLs molekülleri hücre dişında Salmonella enterica hücrelerindeki reseptörler tarafindan algilanır ve biyofilm oluşumu başlatılır. Hafnia alvei hücresinde LuxI tarafindan üretilen AHLs, Salmonella hücresi içinde LuxR tarafindan üretilen AHL reseptörü SdiA proteini tarafindan algilanır (Blana vd., 2017). Salmonella doğrudan AHLs molekülleri üretemediğinden SdiA reseptör proteininin algıladığ1 bu moleküller Salmonella dışındaki bakteriler tarafindan salgılanır. Bilinen örneklere bakarsak kaplumbağalarda Aeromonas bydrophila, farelerde ise Yersinia enterocolitica bakterileri Salmonella'nın biyofilm oluşum mekanizmasını harekete geçiren AHLs moleküllerini salgilarlar (Habyarimana vd., 2014). Sinyal molekülü AHLs üretemeyen Salmonella enterica bakterileri gibi E. coli bakterileri de aynı şekilde AHLs molekülünü üretemediği bilinmektedir (Nguyen vd., 2015).

AI-2 reseptörleri için analiz yöntemlerinin sinırlı olmasından dolayı bir çok bakteri türünde tanımlaması yapılamamıştır (Zhang vd., 2017). Fakat AI-2 otoindükleyiciler için LsrB reseptörü birbirine yakın enterik bakteri E. coli için karakterize edilmiştir (Pereira vd., 2009). LsrB yüksek affiniteli bir substrat bağlayıcı periplazmik proteindir (Pereira vd., 2012). Bu proteinin AI2'leri hücre dışında alg1lama özelliği olduğu bilinmekteyse de AI-2'leri hücre içine aktarma fonksiyonu tespit edilememiştir (Hegde vd., 2011). Hedge ve ark.'nın 2011 yllında yaptıkları çalışmada E. coli bakterilerinin lsrB mutant türevleri kullanılmış ve lsrB geni deaktive olmuş türlerin hala AI-2'leri hücre içine transfer ettiği gözlenmiştir (Hegde vd., 2011). Bir başka çalışmada ise farklı konsantrasyonlardaki AI-2 molekülleri $5 \mathrm{mg} / \mathrm{mL}$ LsrB proteini ile inkübe edilmiştir. Zhang ve ark. 2017'de yaptıkları çalışmada LsrB proteininin ortamdaki AI-2 moleküllerini bağladığ ve LsrB proteinleri denatüre edildiği zaman ise AI-2 moleküllerini bağlayamadığı gözlenmiştir.

QS mekanizmasının üçüncü kısmında ise bakterilerin biyolüminesans üretimi, biyofilm oluşumu, genetik değişim ve virülans faktörü için gerekli genlerin ekspresyonunu aktive etme süreci bulunmaktadır (Hawver vd., 2016).

SdiA'nın hücre içindeki fonksiyonlarında AHLs moleküllerinin reseptör proteini etkilidir. SdiA sayesinde biyofilm ve virülans etki gibi hücre fonksiyonlar1 aktif hale gelir. Fakat bunlara ek olarak SdiA'nın, E. coli kolonilerinin bağırsakta rektal-anal mukoza rahatsızlı̆ında önemli rol oynayan LEE genini hücre içinde etkinleştirdiği de bilinmektedir. $\mathrm{Bu}$ yüzden AHL otoindükleyicilerin olmadığ1 bir ortamda SdiA çalışamamaktadır ve sırasıyla LEE geni aktif olamamaktadır. Böylece E. coli patojenleri koloni oluşturamamaktadır (Kendal ve Sperandio, 2014).

AIPs otoindükleyicileri için QS mekanizmasının üçüncü aşaması ise genel olarak $S$. aureus hücreleri baz alınarak incelenmiştir (Vasquez vd., 2017). QS mekanizmasının ikinci aşaması olan AIP'lerin hücre membraninda bulunan $\mathrm{AgrC}$ proteini tarafindan algilanmasindan sonra fosforil grup hücre içine transfer edilerek AgrA proteinini aktif eder (Wang vd., 2017). Bu fosforil grup ile elde edilen fosforilasyonun $S$. aureus'un virülans etkisi ve hücre içindeki toksinlerin karakterizasyonu ile bağlantılı olduğu görülmektedir (Rajasree vd., 2016).

AI-2 otoindükleyicileri ile yapılan çeşitli araştırmalar bulunmaktadır AI-2 otoindükleyicile- 
rinin biyofilm ve virülans faktörünü aktive eden genlerle ilişkisi tartışmalı konulardan biridir (Kendal ve Sperandio, 2014). Çünkü bu yap1 bakterilere göre değişiklik göstermektedir. Örneğin Salmonella Typhimurium ve Streptococcus bakterilerinin meydana getirdiği AI-2'leri salg1layan luxS geni biyofilm oluşumu bakımından önemli bir rol almaktadır (Wang vd., 2005). Fakat E. coli bakterilerinde AI-2'leri salgilayan luxS geninin biyofilm oluşumunda herhangi bir etkisi olmadığ1 gözlenmiştir (Wang vd., 2005). Gonzalez-Barrios ve ark.'nın 2006 yllinda yaptıkları çalışmada luxS geninin AI-2'leri salgılamasına rağmen biyofilm oluşumunda etkisinin olmadığı tespit edilmiş ve B3022 proteini sayesinde AI-2'lerin biyofilm yapısını oluşturduğu görülmüştür. Ayrıca aynı çalısmada mqsR geni olarak yeniden isimlendirilmiş gen ile kodlanan proteinlerin de virülans etkiyi aktive ettiği tespit edilmiştir. Bu çalışmalar AI-2 otoindükleyicilerin hücre fonksiyonunun bakteri türlerine göre farkll11k gösterebileceğini düşündürmüştür (Wang vd., 2005).

Otoindükleyici sinyal moleküllerinin dışında bakteriyosinlerin de bağırsak florasında QS molekülü olarak kullanıldığı görülmüştür (Arqués vd., 2015). Özellikle laktik asit bakterilerinde QS mekanizmasının bakteriyosinlerle olduğu düşünülmektedir (Rizzello vd., 2012). Rizello ve ark. 2014 yılında yaptıkları çalışmada Lactobacillus plantarum türünün bakteriyosin oluşumuna başlama mekanizması incelenmiştir. Bu amaçla yapilan çalışmada, havuç suyunda bulunan $L$. plantarum ve Bacillus megaterium arasındaki ilişki PCR ile incelenmiş ve $L$. plantarum türünün bakteriyosinler ile B. megaterium üzerine inhibisyon etkisi olduğu gösterilmiştir. Yine bu çalışmada uygunsuz çevre koşullarında yüksek hücre konsantrasyonunda bakteriyosinlerin ortamda gözlenmediği fakat düşük hücre yoğunluğunda bakteriyosinlerin üretiminin olduğunu belirtmişlerdir. Bu durumun QS mekanizmasının bir örneği olabileceği sonucu çıkarılmıştır.

Sinyal moleküllerinin tespit yöntemlerine bakıldığında ise literatürde çeşitli QS saptama sistemleri tarif edilmiş olup, çoğunluğu farklı moleküllerin saptanması için farklı bir afiniteye sahip raportör gen soylarının kullanmasıyla yapılmaktadır. Raportör genleri QS'yi uyaran bir promotörün kontrolü altına sokularak bu türlerin genetik olarak modifiye edilmesi sağlanabilmiştir (Kumar vd., 2016).

QS, bakterilerin belirli bir gen dizisinin ifadesi ile ilgili kolektif kararlar almasını sağlayan düzenleyici bir mekanizmadır ve davranışı koordine etmek için bir iletişim mekanizması olarak, QS'nin biyofilm oluşumu üzerinde bir etkisi olduğu da bulunmuştur (Kumar vd., 2016). Biyofilm oluşumu doğal ortamlarda, klinik ortamlarda ve hastaliklarda kisaca in vivo ve in vitro ortamlarda bakterilerin kendilerini dıș etkenlere karşı korumak için geliştirdiği baskın bir büyüme şekli olarak görülmektedir (Var ve Sağlam, 2017).

\section{Küflerde ve Mayalarda Quorum Sensing Mekanizmas1}

QS mekanizmasının genel olarak bakterilerde meydana geldiği düşünülse de son yıllarda küfler ve mayalarda da bu mekanizmanın görüldüğü gözlenmiştir (Padder vd., 2018; Barriuso vd., 2018). Fakat küfler ve mayalarda görülen QS mekanizmasının ve bu mekanizmada görev alan sinyal moleküllerinin özellikleri henüz net olarak tanımlanamamışır (Barriuso vd., 2018). Küfler için ise QS mekanizması spesifik olmadığ1 gibi çeşitliliği de oldukça fazladır (Padder vd., 2018).

Aspergillus türlerinde QS mekanizmasının ikincil metabolitlerin oluşumu ve ortam koşullarına göre hücre yapısını değiştirme olan morfogenesiz gibi popülasyona bağlı davranışları düzenlediği düşünülmektedir (Barriuso vd., 2018). Bu mekanizmayı sağlayan sinyal molekülünün oksilipinler olduğu bilinmesine rağmen oksilipinlerin nasıl algılandığı ve iletildiği hakkında bilgiler sınırlıdır (Affeldt vd., 2012). Oksilipinler 3,7,11-trimetildodeca-2,6,10-trien-1-ol yapisinda olup farnesol adı ile bilinmektedir (Bacon vd., 2017). Affeldt ve arkadaşları 2012 yilinda yaptıkları çalışmada $A$. flavus kültürlerinin QS mekanizmasinda sinyal mokelü olarak oksilipinleri kullanıyor olduklarını belirtmişlerdir. QS mekanizmas1 oksilipinlerin GprC ve GprD genlerini uyarmak üzerine olup bu genlerin 
uyarilmasiyla A. flavus 'un aflotoksin sentezlenmesi durdurulmaktadir.

Farnesol sinyal molekülünün görev aldığı maya ve küfler arasinda Penicillium sclerotiorum, Histoplasma capsulatum, Ceratocystis ulmi, Saccharomyces cerevisiae, Crytococcus neoformans, Ustilago maydis, Penicillium spp., Fusarium spp., Pleurotus sp., Leptomitus sp., Achlya sp., Saprolegnia sp. say1labilmektedir (Bacon vd., 2017, Raina vd., 2010).

Yapılan bazı gözlemlere göre $S$. cerevisiae mayalarında gerçekleşen QS mekanizması amino asitlerden türetilen aromatik alkoller aracılı̆̆1 ile gerçekleşmektedir. Çoğalan mayaların triptofan ve feniletil alkol üreterek biyofilm ve virülans etkiyi kontrol ettiği düşünülmektedir (Barriuso vd., 2018). Bu mekanizmanın S. cerevisiae mayalarında ARO9 ve ARO10 anahtar genlerinin yüksek hücre yoğunluğu ile uyarıldığ1 ve triptofan ve feniletil alkol üretilerek sinyal molekülü olarak kullanılması ile gerçekleştiği teorisi öne sürülmektedir (Chen ve Fink, 2006).

Bunun yanında insanlarda önemli bir patojen olan Candida albicans mayalarında gerçekleşen QS mekanizmasinda tyrosol, farnesol ve volatile gibi birçok QS molekülünün rol aldığ1 rapor edilmiştir (Padder vd., 2018). Hornby ve arkadaşları 2001 y1lında yaptıkları çalışmada farnesolun $C$. albicans'in virülans etkisini yüksek hücre yoğunluğunda harekete geçirdiğini fakat klinik bulgularda hastalardan alınan dokularda farnesolun tespit edilmediğini belirtmişlerdir. Bu da farnesolun sadece QS mekanizmasını başlatan sinyal molekülü olasılı̆̆ını gösterdiğini belirtmişlerdir (Hornby vd., 2001). Bunun yanında tyyrosolün C. albicans'ta görülen QS mekanizmasindaki fonksiyonu ise farnesolun sınırlı sayıda olduğu zamanlarda devreye girmesi ve farnesol gibi sinyal molekülü görevini üstlenmesi şeklinde düşünülmektedir (Kruppa, 2008). Farnesolun fazla miktarda üretilmesi durumunda QS mekanizması baskilanmakta ve Volatile devreye girerek sinyal molekülü görevini devralmaktadir. Volatilenin bu mekanizması da diğer sinyal molekülleri gibi tam olarak açıklanamamıştır (Schmidt vd., 2015).

\section{QUORUM QUENCHING}

Bu mekanizma ilk kez Dong ve ark.'nın 2002 y1lında yaptıkları çalışmada Bacillus sp. türünde gözlenen AiiA enziminin AHL'leri inhibe ettiğini gözlemeleri ve bu olayı QS bastıran mekanizma olarak tanımlamalarılla ortaya konmuştur (Dong vd., 2007).

QQ mekanizması enzimatik ve kimyasal olarak doğada bulunabilmektedir (Grandclement vd., 2016). Son zamanlarda enzimatik QQ mekanizması hakkinda yapilan incelemeler sonucunda bu mekanizmada iki farklı grubun yer aldığını göstermiştir. Bu iki gruptan Sınıf I olarak adlandirılanı AHL laktonaz, AHL-asilaz ve paraoksonaz içeren enzim kirıcı AHL molekülü olarak tanımlanmıştır. Sınıf II olarak adlandırılan grupta ise, oksidoredüktazı içeren karbonili hidroksile indirgeyen bir enzimin rol oynadiğı görülmüştür. (Chen vd., 2013).

Bunun yanı sıra bitkisel gidaların ekstraktları da QS mekanizması sinyallerine kimyasal olarak benzemekte ve onları inhibe etmektedir. Bu işlemi, sinyal moleküllerinin sentezlenmesini ya da reseptör proteinlerinin aktivitesini azaltarak, sinyal moleküllerini inhibe ederek, sinyal moleküllerini reseptör proteinlerinden ayırarak ve sinyal molekülleri yerine geçerek gerçekleştirir (Truchado vd., 2015).

Bitkisel gıdaların QQ mekanizmasına örnek olarak Almasoud ve ark.'nın 2015 y1linda yaptıkları çalışma verilebilir. Bu çalışmada; laktik ve malik organik asitlerinin E. coli O157:H7 ve Salmonella patojenlerinin QS'deki AI-2 molekülleri üzerine inhibe edici özellikleri gösterilmiştir. E. coli O157:H7'ye ait AI-2'ler laktik asidin \%4 çözeltisinde $\% 80$ oranında inhibe olurken, Salmonella AI-2'leri \%76.6 oraninda inhibe olmuştur. Malik asit için ise, E. coli O157:H7'ye ait AI-2’ler malik asidin \%4 çözeltisinde \%37.5 oraninda inhibe olurken, Salmonella AI-2'leri \%37.5 oraninda inhibe olmuştur (Almasoud vd., 2015).

Bir başka çalışmada ise Luciardi ve ark. tarafından 2016 yilında mandalina esansiyel yağının QS mekanizmasinda görev alan otoindükleyicilerden 
AHL molekülüne etkisi incelenmiştir. Mandalina esansiyel yağını Pseudomonas aeruginosa bakterisinin QS mekanizmasinda kullanılan AHL molekülleri üzerine etkisi bakılırken aynı zamanda, biyofilm ve bakteri gelişmesi üzerine olan inhibisyon etkisi de incelenmiştir. Çalışmada mandalina esansiyel yağın bakteri gelişiminde inhibe etkisi olmadığı görülmüştür. Bunun yanı sıra, mandalina esansiyel yağların AHL moleküllerini $\% 33$, biyofilm yapısını ise $\% 41$ oranında inhibe ettiği görülmüştür.

Duarte ve ark. 2016 yllında, Kişniş esansiyel yağ ve onun majör maddesi olan linaloolun Campylobacter jejuni ve Campylobacter coli ve bunun yan1 sira QS sistemi üzerine antimikrobiyal ve antibiyofilm etkilerini araştırmışlardır. Her iki bileşiğin de anti-Campylobacter aktivitesi gösterdiğinin gözlendiği bildirilmiştir. Araştırmacılar, kişniş yağı ve linalool'un ayrıca, QS inhibisyonu yoluyla biyosensör olarak kullanılan Chromobacterium violaceum ATCC 12472 suşunun (C. violaceum ATCC 12472, $\mathrm{N}$-asilhomoserin laktonları (AHL) tarafindan düzenlenen QS'ye cevaben mor bir pigment olan violaceini sentezleyen bir Gram-negatif bakteridir. AHL, bazı Campylobacter türleri için de tanımlanmış olan Gram negatif bakterilerde QS'ye katılan başlica indüktör moleküllerdir) üretmekte olduğu violacein üretimini inhibe ederken in vitro biyofilm oluşumunu da inhibe ettiği ve biyofilm dağılımına neden olduğunu göstermişlerdir.

Son y1llarda patojenlere karşı birçok QQ etkili doğal ve kimyasal ürünler üzerinde araştırmalar yapılmaktadır. Fakat henüz QQ etkili ürünlerin patojenlere spesifik etkileri, uygulama süresi, şekli ve oranı bilinmemektedir ve bu konu hakkında çalışmalar devam etmektedir (Tang ve Zhang, 2014).

Bir başka QQ mekanizmasını sağlayan moleküller ise küflerin meydana getirdiği ikincil metabolitlerdir. Son yıllarda yaklaşık 33 Penicillium spp'nin salgıladığ1 patulin ve penisilik asit gibi mikotoksinlerle QS mekanizmasının inhibe edilebildiği belirlenmiştir (Kalia, 2013). Ayrıca bir çok bitki türünde etkili olan ve buna bağlı olarak hayvancilık, kümes hayvancilığ ve insanlarda da toksik etki yaratan Fusarium türlerinin ürettiği fumonisin mikotoksinin patojen mikroorganizmaların QS mekanizmasinda görev alan AHL sinyal moleküllerini inhibe edebildiği düşünülmektedir (Bacon vd., 2017). Küflerin QQ mekanizmasını sağlaması hakkında Kong ve ark.'nın 2017 yılında yaptıkları çalışmada su kaynaklı bir patojen olan C. violaceum, LuxI/LuxR tarafindan sentezlenen virülans etki yaratan sinyal moleküllerinin Penicillium sp. SCS-KFD08 tarafindan salgilanan ikincil metabolitler (penicitor A, aculene E ve penicitor B) ile inhibe olduğunu gözlemişlerdir.

Bir mikroorganizmanın bir başka mikroorganizmanın QS mekanizmasında görev alan sinyal moleküllerini inhibe edebildiğini gösteren bazı çalışmalar ile karşılaşılmıştır. Örneğin, Sarfraz ve ark. 2018 y1lında yaptıkları çalışmada patateslerde "Siyah Ayak" hastalığına sebep olan Pectobacterium atrosepticum bakterisinin QS mekanizmasında görev alan AHL sinyal molekülünün Bacillus spp. tarafindan inhibe edildiği tespit edilmiş olup bu hastalı̆̆ın Bacillus spp. ile kontrol altına alınabileceği gösterilmiştir.

\section{SONUÇ}

Halk sağllğ̣ açısından tehdit oluşturan patojenler hakkında yapılan çalışmalar kesintisiz olarak devam etmesine rağmen patojenlerin verdiği zararlar tam anlamiyla kontrol altına alınamamaktadır. Patojenlerin kontrol altına alınamamasina neden olan biyofilm, antibiyotik direnci ve virülans etken gibi etkilerin QS mekanizması sayesinde gerçekleştiği bilinmektedir. Hücre-hücre iletişimi olarak bilinen QS mekanizmasında iletişim molekülü olarak otoindükleyiciler görev almaktadır ve bu moleküller mikroorganizmalara göre çeşitlilik göstermektedir. Bu çeşitlilik QS mekanizmasının önemini arttırmakta ve otoindükleyiciler hakkında çalışmaların genişletilerek her bir patojene özgü moleküllerin tanımlanması gerekmektedir. Böylece patojenler ile mücadelede daha kesin çözümler alınabilecektir.

QS mekanizmas1 patojen bakterilerin yanı sira laktik asit bakterilerinde, küflerde ve mayalarda da gözlenmiştir. QS hakkındaki son çalışmalar 
böylelikle belirli bakteriler ile sınırlı kalmayıp diğer mikroorganizmalarla da gerçekleştirilmeye başlanmıştır.

$\mathrm{Bu}$ konulardaki çalışmaların artması, QS mekanizmasinın ve bunun patojen mikroorganizmalarda biyofilm yapma süreçleri ve virülans etkilerin ortaya çıkıştaki rolleri bu sistemin kontrol altına alınmasıyla önlenebileceği yönünde bilgilerin ulaşmasını sağlamıştır.

Patojenler ile mücadelede mikroorganizmalardaki QS mekanizmasının kontrol altına alınması QQ mekanizması ile QS mekanizmasında görev alan otoindükleyici moleküllerin inhibisyonunu temel almaktadir. Bu kapsamda QQ mekanizması hakkında birçok çalışma yapılmaktadır. $\mathrm{Bu}$ mekanizma hakkında çalışmaların ilerleyen yıllarda artmasıyla yeni QS mekanizmasını inhibe eden maddelerin gözleneceği düşünülmektedir.

Her ne kadar QS mekanizmasi sinyal moleküllerini engelleyen QQ mekanizmas1 patojenlerin verdiği zararları engelleme konusunda umut verici olsa da mikroorganizmalarda stres yaratan bu çevresel koşullara karşı genetik mekanizmaların varlığı, onları bu etkileşimleri metabolik aktiviteleri ile dengelemek üzere evrimleştirebilir.

QS mekanizmasının sinyal moleküllerinin biyofilm, virülans etki, antibiyotik dirençliliği ve toksin üretimi dışında varsa başka fonksiyonları da olup olmadığı yönünde farklı çalışmalar kurgulanmalıdır. Buna ek olarak patojenlerin bilinenler ve çalışılanların dışında QS mekanizmasinda kullanılan sinyal moleküllerinin varlığ1 da sorgulanmalıdır. Küfler ve mayalarda QS mekanizması tam olarak tanımlanmamış olması bu konuda çalışmaların çoğaltılması gerekliliğini ortaya koymaktadır. Özellikle QS ve QQ mekanizmalarıyla küflerde toksin sentezinin durdurulmasına yönelik elde edilecek veriler özellikle gıda ve tarım ürünlerindeki en önemli problemlerden biri olan mikotoksin problemlerinin çözümüne de katkı sunacaktır.

\section{KAYNAKLAR}

Affeldt, K. J., Brodhagen, M., Keller, P. N. 2012. Aspergillus oxylipin signaling and quorum sensing pathways depend on G protein-coupled receptors. Toxin, 4: 695-717.

Almasoud, A., Hettiarachchy, N., Rayaprolu, S., Babu, D., Kwon, Y. M., Mauromoustakos, A. (2015). Inhibitory effects of lactic and malic organic acids on autoinducer type 2 (AI-2) quorum sensing of Escherichia coli $\mathrm{O} 157: \mathrm{H} 7$ and Salmonella Typhimurium. LWT - Food Sci Technol, 66 (2016): 560-564.

Anbazhagan, D., Mansor, M., Yan, G. O. S.,Yusof, M. Y. M., Hassan, H., Sekaran, D. S. (2012). Detection of quorum sensing signal molecules and identification of an autoinducer synthase gene among biofilm forming clinical isolates of Acinetobacter spp., PLos ONE, 7(7): 112.

Amaral, G. R. S., Campeao, M. E. (2015). Finding diagnostic phenotypic features of Photobacterium in the genome sequences. Antonie Leeuwenhoek, 107: 1351-1358.

Arqués, J. L., Rodríguez, E., Langa, S., Landete, J. M., Medina, M. (2015). Antimicrobial activity of lactic acid bacteria in dairy products and gut: effect on pathogens. BioMed Res International,1-9.

Bacon, C. W., Hinton, D. M., Mitchell, T. R. (2017). Is quorum signaling by mycotoxins a new risk-mitigating strategy for bacterial biocontrol of Fusarium verticillioides and other endophytic fungal species? J Agric. Food Chem., 65 (33): 7071-7080.

Barrios, A. F. G., Zuo, R., Hashimoto, Y., Yang, L., Bentley, W. E., Wood, T. K. (2006). Autoinducer 2 controls biofilm formation in Escherichia coli through a novel motility quorumsensing regulator (MqsR, B3022). J Bacteriol, 188 (1): 305-316.

Barrios, G. F. A., Zuo, R., Hashimoto, Y., Yang, L., Bentley, W. E., Wood, T. K. (2006). Autoinducer 2 controls biofilm formation in Escherichia coli through a novel motility quorumsensing regulator (MqsR, B3022). J Bacteriol, 188 (1): 305-316.

Barriuso, J., Hogan, D. A., Keshavarz, T., Martinez, M. J. (2018). Role of quorum sensing and chemical communication in fungal 
biotechnology and pathogenesis. FEMS Microbiol Rev, 42(5): 627-638.

Bhardwaj, A. K., Vinothkumar, K., Rajpara, N. (2013). Bacterial quorum sensing inhibitors: attractive alternatives for control of infectious pathogens showing multiple drug resistance. Recent Patents on Anti-Infective Drug Discov, 8(1): 6883.

Blana, V., Georgomanou, A., Giaouris, E. (2017). Assessment of the effect of a Salmonella enterica Serovar Typhimurium culture supernatant on the single-cell lag time of foodborne pathogens. Food Control, 80: 83-91.

Bosgelmez-Tinaz, G. (2013). Disruption of bacterial cell-to-cell communication (quorum sensing): a promising novel way to combat bacteria-mediated diseases. MÜSBED, 3(3): 159163.

Chen, H., Fink, G. R. 2006. Feedback control of morphogenesis in fungi by aromatic alcohols. Genes Dev, 20(9): 1150-1161.

Chen, F., Gao, Y., Chen, X., Yu, Z., Li, X. (2013). Quorum quenching enzymes and their application in degrading signal molecules to block quorum sensing-dependent infection. Int J Mol Sci, 14:17477-17500.

Deep, A., Chaudhary, U., Gupta, V. (2011). Quorum sensing and bacterial pathogenicity: from molecules to disease. J Lab Phys, 3(1): 4-11.

Dong, Y., Wang, L., Zhang, L. (2007). Identification of quorum-quenching n-acyl homoserine lactonases from Bacillus species. Appl Environ Microbiol, 68(4): 1754-1759.

Dong, Y., Wang, L., Zhang, L. (2007). Quorumquenching microbial infections: mechanisms and implication. Phil. Trans. R. Soc. B., 362: 1201-1211.

Duanis-Assaf, D., Steinberg, D., Chai, Y., Shemesh, M. (2016). The Lux S based quorum sensing governs lactose induced biofilm formation by Bacillus subtilis. Microbiol. 6: 151 .

Duarter, A., Luis, A., Oleastro, M., Domingues, F. C. (2016). Antioxidant Properties of coriander essential oil and linalool and the irpotential to control Campylobacter spp.. Food Control, 61(2016): 115-122.

Eberhard, A., Burlingame, A. L., Eberhard, C., Kenyon, G. L., Nealson, K. H., Oppenheimer, N. J. (1981). Structural identification of autoinducer of photobacterium fischeri luciferase. Biochem, 20(9): 2444-2449.

Erzinger, G. S., Schmoeller, F., Pinto, L. H., Ame rico1, L., Hemmersbach, R., Hauslage, J., H ader, D. (2018). Bioluminescence systems in environmental biosensors. Bioassays, 241-262.

Fuqua, W. C., Winans, S. C., Greenberg, E. P. (1994). Quorum Sensing in Bacteria: the LuxRLuxI Family of Cell Density-Responsive Transcriptional Regulators. J Bacteriol, 176(2): 269275.

Grandclement, C., Tannieres, M., Morera, S., Dessaux, Y., Faure, D. (2016). Quorum Quenching: Role in Nature and Applied Developments. FEMS Microbiol Rev, 40: 86-116.

Habyarimana, F., Sabag-Daigle, A., Ahmer, B. M. M. (2014). The SdiA-regulated gene $s r g E$ encodes a type III secreted effector. J Bacteriol, 196(12): 2301-2312.

Hawver, L. A., Jung, S. A., Ng, W. (2016). Specificity and complexity in bacterial quorumsensing systems. FEMS Microbiol Rev, 40(5): 738752.

Hegde, M., Englert, D. L., Schrock, S., Cohn, W. B., Vogt, C., Wood, T. K., Manson, M. D., Jayaraman, A. (2011). Chemotaxis to the Quorum-Sensing Signal AI-2 Requires the Tsr Chemoreceptor and the Periplasmic LsrB AI-2Binding Protein. J Bacteriol, 193(3): 768-773.

Hornby, J. M., Jensen, E. C., Lisec, A. D., Tasto, J. J., Jahnke, B., Shoemaker, R., Dussault, P., Nickerson, K. W. 2001. Quorum Sensing in the dimorphic fungus Candida albicans is mediated by farnesol. Appl Environ Microbiol, 67(7): 2982-2992.

Johensen, P., Jespersen, L. (2017). Impact of quorum sensing on the quality of fermented foods. Curr Opin Food Sci, 13:16-25.

Johnson, J. G., Wang, B., Debelouchina, G. T., Novick, R. P., Muir, T. W. (2015). Increasing AIP 
macrocycle size reveals key features of agr activation in Staphylococcus aureus. ChemBioChem, 16: 1093-1100.

Kalia, V. C. (2013). Quorum sensing inhibitors: an overview. Biotechnol Adv, 31: 224-245.

Karaboz, İ., Sukatar, A., (2004). Bakterilerde sosyal davranışlar (bakterilerde iletişim mekanizmalar1). Orlab On-Line Mikrobiyol Derg, 2(5): 23-32.

Kendal, M. M., Sperandio, V. (2014). Cell-to-cell signaling in E. coli and Salmonella. EcoSal Plus., 6(1): $1-22$.

Kong, F. D., Zhou, L. M., Ma, Q. Y., Huang, S. Z., Wang, P., Dai, H. F., Zhao, Y. X. (2017). Metabolites with gram-negative bacteria quorum sensing inhibitory activity from the marine animal endogenic fungus Penicillium sp. SCS-KFD08. Arch Pharm Res, 40(1): 25-31.

Kruppa, M. 2008. Quorum sensing and Candida albicans. Mycoses, 52: 1-10.

Kumar, J. S., Umesha, S., Prasa, K. S., Niranjana, P. (2016). Detection of quorum sensing molecules and biofilm formation in ralstonia solanacearum. Curr Microbiol, 72: 297-305.

Litrenta, J., Oetgen, M. (2017). Hafnia alvei: a new pathogen in open fractures. Trauma Case Rep, 8: $41-45$.

Luciardi, M. C., Blazquez, M. A., Cartagena, E., Bardon, A., Arena, M. A. (2016). Mandarin essential oils inhibit quorum sensing and virulence factors of Pseudomonas aeruginosa. LWT - Food Science and Technology, 68: 373-380.

Nguyen,Y. Nguyen, N. X., Rogers, J. L., Liao, J., MacMillan, J. B., Jiang, Y., Sperandio, V. (2015). Structural and mechanistic roles of novel chemical ligands on the SdiA quorum-sensing transcription regulator. $M$ Biol, 6(2): 1-10.

Okutsu, N., Morohosi, T., Xie, X., Kato, N., Ikeda, T. (2016). Characterization of $N$ acylhomoserine lactones produced by bacteria 1solated from industrial cooling water systems. Sensors, 16(44): 1-9.
O’Toole, G. A. (2016). Classic spotlight: quorum sensing and the multicellular life of unicellular organisms. J Bacteriol, 198(1): 601.

Padder, S. A., Prasad, R., Shah, A. H. (2018). Quorum sensing: a less known mode of communication among fungi. Microbiol Res, 210: 51-58.

Pereira, C. S., Regt, A. K., Brito, P. H., Miller, S. T., Xavier, K. B. (2009). Identification of functional LsrB-Like autoinducer-2 receptors. $J$ Bacteriol, 191(22): 6975-6987.

Pereira,C. S., Thompson, J. A., Xavier, K. B. (2012). AI-2-mediated signalling in bacteria. FEMS Microbiol Rev., 37: 156-181.

Raina, S., Odell, M., Keshavarz, T. 2010. Quorum sensing as a method for improving 643 sclerotiorin production in Penicillium sclerotiorum. J. Biotechnol, 148: 91-98.

Rajasree, K., Fasim, A., Gopal, B. (2016). Conformational features of the Staphylococcus aureus agrA-promoter interactions rationalize quorum-sensing triggered gene expression. Biochem Biophy Rep, 6: 124-134.

Rampioni, G., Leoni, L., Williams, P. (2014). The art of antibacterial warfare: deception through interference with quorum sensing-mediated communication. Bioorg Chem, 55: 60-68.

Ray, V. A., Visick, K. L. (2012). LuxU connects quorum sensing to biofilm formation in Vibrio fischeri. Mol Microbiol, 86(4), 954-970.

Rizzello, C. G., Filannino, P., Cagno, R., Calasso, M., Gobbetti, M. (2014). Quorum-sensing regulation of constitutive plantaricin by Lactobacillus plantarum Strains under a model system for vegetables and fruits. Appl Environ Microbiol, 80(2): 777-787.

Roux, A., Todd, D. A., Velazquez, J. V., Cech, N. B., Sonenshein, A. L. (2014). CodY mediated regulation of the Staphylococcus aureus Agr system integrates nutritional and population density signals. J Bacteriol, 196(6):1184-1196.

Rutherfor, S. T. and Bassler, B. L. (2012). Bacterial quorum sensing: its role in virulence and 
possibilities for its control. Cold Spring Harbor Perspect Med, (2): 1-25.

Sarfraz, S., Sahi, S. T., Rehman, A., Rajput, N. A., Alam, M. W., Hameed, A., Riaz, K. (2018). Antagonistic potential of Bacillus spp. associated with potato rhizosphere for controlling pectobacterium based infections in potato. Uluslar arası Tarım, Çevre ve Sağlık Kongresi, 2628 Ekim, Aydın, Türkiye.

Schmidt, R., Etalo, D. W., Jager, V., Gerards, S., Zweers, H., Boer, W., Garbeva, P. 2016. Microbial small talk: volatiles in fungal-bacterial interactions. Front Microbiol, 6(1495): 1-12.

Skandamis, P. N., Nychas, G. E. (2012). Quorum sensing in the context of food microbiology. Appl Environ Microbiol, 78(16): 5473-5482.

Song, X., Qiu, H., Xiao, X., Cheng, Y., Li, W., Sheng, G., Li, X., Yu, H. (2014). Determination of autoinducer-2 in biological samples byhighperformance liquid chromatography with fluorescencedetection using pre-column derivatization. J Chromatogr A, 1361: 162-168.

Tang, K., Zhang, X. (2014). Quorum quenching agents: resources for antivirulence therapy. Mar Drugs, 12: 3245-3282.

Traber, K. E., Lee, E., Benson, S., Corrigan, R., Cantera, M., Shopsin, B., Novick, R. P. (2008). Agr function in clinical Staphylococcus aureus isolates. Microbiol, 154: 2265-2274.

Truchado, P., Larrosa, M., Castro-Ibanez, I., Allende, A. (2015). Plant food extracts and phytochemicals: their role as quorum sensing inhibitors. Trends in Food Science \& Technology, 43: 189-204.

Vasquez, J. K., Tal-Gan, Y., Cornilescu, G., Tyler, K. A., Blackwel, H. E. (2017). Simplified AIP-II peptidomimetics are potent inhibitors of Staphylococcus aureus AgrC quorum sensing receptors. ChemBioChem, 18(4): 413-423.

Var, I., Sağlam, S. 2017. "Biofilm Structure of Foodborne Pathogens". Antimicrobial Research: Novel bioknowledge and educational programs
Microbiology Book Series, No: 6-Formatex Research center. Edited by A.Mendez-Vilas. Printed in Spain. s.301-307.

Wang, B., Zhao, A., Novick, R., Muir, T. W. (2014). Activation and inhibition of the receptor histidine kinase AgrC occurs through opposite helical transduction motions. Mol Cell., 53(6): 929-940.

Wang, B., Zhao, A., Xie, Q., Olinares, P. D., Chait, B. T., Novick, R., Muir, T. W. (2017). Functional plasticity of the AgrC receptor histidine kinase required for Staphylococcal virulence. Cell Mic Biol, 24: 1-11.

Wang, H., Tu, F., Gui, Z., Lu, X., Chu, W. (2013). Antibiotic resistance profiles and quorum sensing-dependent virulence factors in clinical isolates of Pseudomonas aeruginosa. Indian J Microbiol, 53(2): 163-167.

Wang, L., Li, J., March, J. C., Valdes, J. J., Bentley, W. E. (2005). luxS-Dependent gene regulation in Escherichia coli K-12 revealed by genomic expression profiling. J Bacteriol, 187(24): 83508360.

Whitehead, N. A., Barnard, A. M. L., Slater, H., Simpson, N. J. L., Salmond, G. P. C. (2001). Quorum-sensing in gram-negative bacteria. FEMS Microbiol Rev, 25: 365-404.

Zan, J., Cicirelli, E. M., Mohamed, N. M., Sibhatu, H., Kroll, S., Choi, O., Uhlson, C. L., Wysoczinski, C. L., Murphy, R. C., Churchill, M. E. A., Hill, R. T., Fuqua, C. (2012). Acomplex Luxr-Luxi type quorum sensing network in a roseobacterial marine sponge symbiont activates flagellar motility and inhibits biofilm formation. Mol Microbiol., 85(5): 1-17.

Zhang, Y., Qi, K., Jing, Y., Zuo, J., Hu, J., Lv, X., Chen, Z., Mi, R., Huang, Y., Yu, S., Han, X. (2017). LsrB-based and temperature-dependent identification of bacterial AI-2 receptor. $A M B$ Expr, 7(188): 1-10. 